\title{
Measurement of shoulder related disability: results of a validation study
}

\author{
P Croft, D Pope, M Zonca, T O’Neill, A Silman
}

\begin{abstract}
Objective-To develop and validate a questionnaire to quantify disability associated with shoulder symptoms.

Methods-A set of questions relevant to shoulder symptoms from a general disability interview was developed and the questionnaire applied to a cross-sectional population survey and a prospective study of general practice attenders. Subjects included adults who reported current shoulder pain in a population survey and patients from three general practices who attended with shoulder symptoms during a six month period. The main outcome measures were: frequency of problems with daily living related to shoulder symptoms, total score on 22-item disability questionnaire, and measures of shoulder movement.

Results-A higher proportion $(80 \%)$ of patients attending their general practitioner with shoulder symptoms had five or more disabilities compared with subjects reporting shoulder pain in a community survey (34\%). The ranked frequency with which each disability was reported was similar in the two groups, although sleep disturbance was the most common problem in consulters. Selfreported disability is correlated with measures of restricted shoulder movement. Conclusion-This disability questionnaire was simple to complete and should prove useful for both general practice and population-based studies of shoulder pain.
\end{abstract}

(Ann Rheum Dis 1994; 53: 525-528)

Painful shoulder disorders are common. They make up a substantial proportion of new referrals to rheumatology outpatient clinics in the United Kingdom. ${ }^{1}$ After consultations for back pain, they are the second most frequent acute musculo-skeletal complaint presenting in general practice. ${ }^{2}$ There is also a substantial burden of shoulder pain in the community for which consultation is not sought, the estimated prevalence of current shoulder pain being 7\% in both Swedish and United Kingdom populations. $^{3-4}$ This prevalence increases sharply with age, with one in five of those aged over 70 suffering from a shoulder disorder. ${ }^{5}$ The substantial proportion of adults affected in their middle years has important socio-economic implications because the associated disability is likely to result in time lost from work.
Shoulder syndromes cause pain and restricted movement on examination. However, it is the associated disability which may provide the best measure of prognosis and response to therapy, and various instruments have been constructed in an attempt to quantify this. ${ }^{6}$ As yet none is generally accepted. We have developed a simple questionnaire, designed for self-completion, for the assessment of restriction in everyday activities resulting from shoulder symptoms. The purpose of the study was to validate the score obtained from this questionnaire by testing two hypotheses: (1) patients attending their general practitioner because of shoulder pain will have a higher disability score than patients reporting shoulder pain in the general population; (2) restriction of shoulder movement on examination correlates with disability score.

\section{Subjects and methods}

DEVELOPMENT OF DISABILITY QUESTIONNAIRE The basic approach to developing the questionnaire was similar to a method described by Roland and Morris for measuring low back pain disability in primary care. Questions considered relevant to the shoulder were selected from the Functional Limitations Profile (FLP), an extensive interview-based questionnaire validated for use in the general population, including domestic, recreational and psycho-social problems. In addition physiotherapists and occupational therapists were asked to construct lists of activities which were likely to be affected by shoulder pain or stiffness. Similar lists were constructed after interviews with 10 general practice patients who had established shoulder problems. Using all these sources a 22 item questionnaire was developed by adding "because of your shoulder" to the original FLP questions (Appendix).

\section{STUDY POPULATIONS}

Two study groups were assessed to test the validity of this questionnaire. The first group comprised 71 subjects with shoulder pain identified from a postal survey of pain complaints. This had been undertaken in a population of adults aged 18 years and over, sampled randomly from the age-gender register of a local general practice, and described in full in an earlier publication. ${ }^{8}$ In response to a questionnaire, these subjects answered positively to an enquiry about any shoulder pain during the previous month 
Table 1 Characteristics of populations studied

\begin{tabular}{|c|c|c|c|c|c|c|c|}
\hline \multirow[t]{2}{*}{ Study' group } & \multirow[t]{2}{*}{ Inclusion criteria } & \multirow[t]{2}{*}{ No } & \multicolumn{2}{|c|}{ Female } & \multicolumn{3}{|l|}{ Age } \\
\hline & & & No & $(\%)$ & Mean & $(S D)$ & Range \\
\hline Community & Shoulder pain in past month lasting $>24$ hours & 67 & 48 & 72 & 65 & $9 \cdot 0$ & $24-85$ \\
\hline $\begin{array}{l}\text { General practice } \\
\text { attenders }\end{array}$ & $\begin{array}{l}\text { Attending primary care with a new episode of } \\
\text { shoulder pain }\end{array}$ & 54 & 28 & 52 & 51 & $17 \cdot 4$ & $19-82$ \\
\hline
\end{tabular}

$\mathrm{SD}=$ Standard deviation.

which had lasted for more than 24 hours. The second group consisted of 54 patients who had consulted with a new episode of shoulder pain in one of three other local general practices during a six month period.

\section{SURVEY METHOD}

Both community-ascertained shoulder sufferers and general practice attenders were asked to complete the questionnaire shown in the Appendix. In addition, the subjects identified from the population survey were invited to attend for an examination of their shoulder joint by a research general practitioner. It involved measuring both active and passive abduction and internal and external rotation using an oil-based plurimeter (J Rippstein, personal communication). Shoulder power was measured in kilograms of weight of resisted abduction using a spring balance, as described by Constant. ${ }^{9}$ Finally, an assessment of global restriction in shoulder movement was made by asking the subject to rotate the arm internally at the shoulder and place the tip of the thumb as high up the spinal column as possible. The distance in centimetres from the tip of the thumb to the occiput was measured.

ANALYSIS

The number and percentage of each of the two study groups who gave positive answers to the items on the shoulder questionnaire were calculated and the rank order of these disabilities analysed for both study groups. The correlation between the two ranks was compared using Spearman's rank correlation coefficient. The association between range of movement, strength of abduction and dis-

Table 2 The six most frequently reported items of shoulder related disability. Community and general practice attenders

\begin{tabular}{|c|c|c|c|c|c|c|}
\hline \multirow[t]{2}{*}{ Rank } & \multicolumn{3}{|l|}{ Community $(n=67)$} & \multicolumn{3}{|l|}{ General practice $(n=54)$} \\
\hline & Problem item & No & $(\%)$ & Problem item & No & $(\%)$ \\
\hline 1 & Avoid heavy jobs & 27 & 40 & Change position in bed & 39 & 72 \\
\hline 2 & Change position in bed & 26 & 39 & Sleep less well & 39 & 72 \\
\hline 3 & Moving arm/hand & 24 & 36 & Putting on jersey & 38 & 70 \\
\hline 4 & Putting on jersey & 22 & 33 & Moving arm/hand & 37 & 69 \\
\hline 5 & Fastening clothes & 20 & 30 & Avoid heavy jobs & 36 & 67 \\
\hline 6 & Dress slower & 20 & 30 & Dress slower & 32 & 59 \\
\hline
\end{tabular}

Note: the rank correlation co-efficient for all the items was $0 \cdot 84$

Table 3 Total number of items chosen on disability questionnaire. Community and general practice attenders

\begin{tabular}{lllllc}
\hline Total number of items chosen: & \multicolumn{2}{c}{ Community } & $(n=67)$ & & \multicolumn{2}{c}{ General practice $(n=54)$} \\
\cline { 2 - 3 } & No & & & No & $(\%)$ \\
\hline 0 & 18 & 27 & & 1 & 2 \\
$1-4$ & 26 & 39 & & 10 & 18 \\
$5+$ & 23 & 34 & & 43 & 80 \\
\hline
\end{tabular}

ability score was investigated after stratifying the disability score into three groups: (1) those reporting no problem; (2) those reporting one to four items of disability and (3) those reporting five or more items. Each of the examination measures was dichotomised about their median value. Odds ratios (with their $95 \%$ confidence intervals) were calculated to estimate the associations between examination measures and disability score. Odds ratios for those with a disability score of 1-4 and a score of 5 or more were calculated separately relative to subjects reporting no disability. A Chisquare test for trend was applied to the change in examination scores across the three levels of disability.

\section{Results}

The characteristics of the two populations studied are shown in table 1 . In the community survey 67 of 71 subjects identified as having shoulder pain completed the disability questionnaire of whom 56 agreed to participate in the full examination. The 11 subjects who refused examination were similar in terms of age, sex and disability score to the 56 participants. The subjects who were examined were more likely to be female and had an older mean age than the general practice attenders. This difference may reflect demographic variations in consultation behaviour or differences in the perception of severity of shoulder pain.

The six most frequently reported items of shoulder related disability in each study group are shown in table 2 . The rank order of the frequency of all the disability items was similar in both groups, with difficulties in dressing being the most prominent set of problems. In neither group was there more than a small number of patients who required assistance with dressing. Sleep disturbance was the most common problem in the general practice group, being reported three times more often than in the community sample. There was no obvious association of gender with level of disability in either study population.

General practice attenders reported substantially more disabilities than the community sample, with $80 \%$ of the former reporting five or more disabilities compared with $34 \%$ of the latter, a difference of $46 \%(95 \%$ CI $30 \%-61 \%)$. This is summarised in table 3 . In addition the proportion of subjects who reported no restriction at all in every day activities because of their shoulder symptoms was higher in the community sample $(27 \%)$ than in the general practice group $(2 \%)$.

The relationship between the disability score in the community group and the various measures of shoulder restriction are shown in 
Table 4 Association between disability score and shoulder restriction measures in 56 subjects from the community sample.

\begin{tabular}{|c|c|c|c|c|c|c|c|c|}
\hline \multirow[t]{2}{*}{ Movement } & \multirow[t]{2}{*}{ Median } & \multirow{2}{*}{$\frac{\text { Disability score } 0}{O R^{I}}$} & \multicolumn{2}{|c|}{ Disability score 1-4 } & \multicolumn{2}{|c|}{ Disability score $>5$} & \multicolumn{2}{|c|}{ Trend analysis } \\
\hline & & & $O R$ & $95 \% C I^{2}$ & $O R$ & $95 \% C I$ & Chi-square & $p$ value \\
\hline Abduction & $168^{\circ}$ & $1 \cdot 0$ & $1 \cdot 7$ & $0 \cdot 4-6 \cdot 6$ & $6 \cdot 6$ & $1.5-30 \cdot 0$ & $13 \cdot 5$ & 0.000 \\
\hline Internal rotation & $61^{\circ}$ & $1 \cdot 0$ & $1 \cdot 8$ & $0 \cdot 4-7 \cdot 4$ & $3 \cdot 2$ & $0 \cdot 7-15 \cdot 3$ & $4 \cdot 6$ & 0.031 \\
\hline External rotation & $74^{\circ}$ & $1 \cdot 0$ & $4 \cdot 6$ & $1 \cdot 0-20 \cdot 0$ & $4 \cdot 0$ & $0 \cdot 8-20 \cdot 0$ & $3 \cdot 1$ & 0.079 \\
\hline Thumb on spine & $32 \mathrm{~cm}$ & $1 \cdot 0$ & $1 \cdot 7$ & $0 \cdot 4-6 \cdot 6$ & $5 \cdot 7$ & $1 \cdot 3-24 \cdot 4$ & $10 \cdot 1$ & 0.002 \\
\hline Power* & $5.4 \mathrm{~kg}$ & $1 \cdot 0$ & $3 \cdot 5$ & $0 \cdot 5-26 \cdot 2$ & $7 \cdot 0$ & $0.9-55.4$ & $2 \cdot 0$ & $0 \cdot 153$ \\
\hline
\end{tabular}

'Odds ratio.

$295 \%$ confidence interval

^ Based on 28 subjects only.

table 4. For all measurements, the likelihood of a restriction below the median increased with disability score. There were clear trends of increasing restriction with rising level of disability for all measures except external rotation. Power was only measured in 28 subjects because pain or restricted abduction made the measurement impossible in the other 28; the trend of disability score with this measure was not statistically significant.

\section{Discussion}

In this study a simple questionnaire for completion by patients with shoulder complaints has been developed. It includes items perceived to be important by both patients and therapists, as well as questions related to psychological well being, such as irritability and loss of appetite. All relevant areas of activity mentioned by patients and therapists were included and, as a result, we consider that this instrument has both face and content validity. It is also simple to use in practice and easy to score.

Our first hypothesis was that subjects attending general practitioners with shoulder pain would have higher levels of disability than those identified by population screening. This was shown to be the case. The rank order of disabilities was similar in both groups suggesting that progression of shoulder problems is being reflected rather than a difference in global severity alone.

The second hypothesis was that disability scores would reflect more objective measures of shoulder restriction. This was confirmedthose in the lower half of the range for the measures of shoulder restriction were more likely to report higher levels of disability. These trends were observed for all the measures, apart from external rotation. It is possible that those activities of daily living which are important to the patient are more dependent on abduction and internal rotation than on external rotation. The measure of power also showed a correlation with disability, but this was a less helpful standard because it proved difficult to measure in all subjects.

Generic disability questionnaires, such as the Health Assessment Questionnaire (HAQ), ${ }^{10}$ have been used widely in rheumatoid arthritis and in other diseases which can involve many parts of the body. The difficulty of applying such measures to more localised syndromes is that they may be insensitive to the specific disabilities that such conditions may cause. We have adopted therefore the strategy proposed by Roland and Morris ${ }^{7}$ who developed a low back pain-specific disability score based on the Functional Limitations Profile (FLP).

Disability scores, specific for the shoulder, have been described previously. ${ }^{6}$ The Shoulder Pain and Disability Index (SPADI) was found to have good internal consistency, test re-test reliability, and criteria and construct validity in a sample of 37 male outpatients with shoulder complaints. The simplicity of the SPADI suggests its suitability for self-completion by hospital patients with shoulder problems. It has not, however, been investigated in a community setting. Furthermore, this instrument contains only two of the categories of disability outlined in the Functional Limitations Profile (FLP), namely body care and mobility. The FLP describes 10 other areas of disability which in total may reflect more truly the range of problems linked to shoulder pain. One such area is sleep disturbance which was the most frequent disability reported in our samples.

The disability questionnaire outlined in this study contains 22 items covering 11 of the 12 disability categories in the original FLP. A comprehensive score can therefore be calculated to reflect the disability associated with shoulder complaints. The next investigation of the questionnaire will be to assess its sensitivity to change by following groups of patients over time. The Roland and Morris low back pain questionnaire has been found to perform as well in this regard as the full-length FLP. ${ }^{11}$ It is likely that other joint-specific questionnaires constructed in the same way, such as this shoulder schedule, would function similarly but this remains to be tested.

One issue that has not been addressed is the repeatability of the instrument. There is an inherent difficulty in measuring repeatability in disorders which are subjeçt to considerable change over time within individuals, both in the short and longer term. If the questionnaire is administered too soon the subject may remember their answers and so recall is being tested. More prolonged intervals between questionnaires may be associated with true patient change which might then be interpreted as poor repeatability.

This study has confirmed other work suggesting that disability is common in relation to shoulder pain seen in primary care and in the community. ${ }^{12}$ There is a need for studies of natural history, aetiology and early intervention in the community to establish the 
extent to which such disability may be preventable. The instrument described here may prove helpful in such studies as a measure of severity and outcome.

We thank Carl Whitehouse, John Sandars, Gerald Coope, Roger Gadsby and the partners, staff and patients at the Rusholme Health Centre, Barlow Medical Centre, Wilmslow Road and Bollington practices.

1 Bamji A N, Dieppe P A, Haslock D I, Shipley M E. What do rheumatologists do? A pilot audit study. $\mathrm{Br} f$ Rheumatol 1990; 29: 295-8.

2 Office of Population Census and Surveys. Royal College of General Practitioners. Department of Health and Social Security. Morbidity Statistics from General Practice. Security. Morbidity Statistics from General Practice

3 Jacobsson L, Lingarde F, Manthorpe R. The commonest rheumatic complaints of over six weeks duration in a twelve-month period in a defined Swedish population: prevalence and relationships. Scand f Rheumatol 1989; 18: 353-60.
4 Badley E, Tennant A. Changing profile of joint disorders with age: findings from a postal survey of the population of Calderdale, West Yorkshire, United Kingdom. Ann Rheum Dis 1992; 51: 366-71.

5 Chakravarty K, Webley $M$. Disorders of the shoulder: an often unrecognised cause of disability in elderly people. BMF 1990; 300: 848-9.

6 Roach K E, Budiman-Mak E, Songsiridej N, Lertratanakul Y. Development of a shoulder pain and disability index. Arthritis Care Res 1991; 4: 143-9.

7 Roland M, Morris R. A study of the natural history of back pain. Part I: Development of a reliable and sensitive measure of disability in low back pain. Spine 1983; 8: 141-4.

8 Croft P, Rigby A S, Boswell R, Schollum J, Silman A J. The prevalence of chronic widespread pain in the general population. $f$ Rheumatol 1993; 20: 710-3.

9 Constant $C R$. Historial background, anatomy and shoulder function. Baillieres Clin Rheumatol 1989; 3: 429-35.

10 Fries J F, Spitz P, Kraines G, Holman H R. Measurement of patient outcome in arthritis. Arthritis Rheum 1980; 23:

11 Deyo R. Comparative validity of the Sickness Impact Profile and shorter scales for functional assessment in low back pain. Spine 1986; 11: 951-4

12 Chard M D, Hazleman R, Hazleman B L, King R H, Reiss B B. Shoulder disorders in the elderly: A community survey. Arthrits Rheum 1991; 34: 766-9.

\section{Appendix}

When your shoulder hurts, you may find it difficult to do some of the things you normally do.

This list contains some sentences that people have used to describe themselves when they have trouble with their shoulder. When you read them, you may find that some stand out because they describe you TODAY. As you read them, think of yourself TODAY.

When you read a sentence that describes you today, please tick the 'YES' box. If the sentence does not describe you, then please tick the 'NO' box and go on to the next one.

Please only tick the 'YES' box for a sentence if you are sure that it describes you today.

YES NO

1 Because of pain in my shoulder, I move my arm or hand with some difficulty.

2 I do not bath myself completely because of my shoulder.

3 Because of my shoulder trouble, I get dressed with help from someone else.

4 I get dressed more slowly than usual because of my shoulder.

5 Because of my shoulder trouble, I fasten my clothing with some difficulty. (eg buttons, shoelaces, ties, zips or bra).

6 I have trouble putting on a jersey, coat, shirt, blouse or jacket because of my shoulder problem.

7 Because of my shoulder problem I change position frequently in bed at night.

8 I cannot lie on my right side at night because of my shoulder.

9 I cannot lie on my left side at night because of my shoulder.

10 I stay at home most of the time because of my shoulder problem.

11 Because of my shoulder problem I do less of the daily household jobs than I would usually do.

12 I avoid heavy jobs around the house because of my shoulder trouble.

13 Because of my shoulder I do not carry any shopping.

14 Because of my shoulder trouble, I am cutting down on some of my usual sports or more active pastimes.

15 Because of my shoulder trouble, I am not doing any of my usual physical recreation or more active pastimes.

16 Because of my shoulder, I try to get other people to do things for me.

17 My shoulder makes me more irritable and bad tempered with people than usual.

18 Because of my shoulder, I have more minor accidents. (eg dropping things).

19 I sleep less well because of my shoulder.

20 Because of my shoulder, I rest more often during the day.

21 My appetite is not very good because of my shoulder problem.

22 Because of my shoulder, I have trouble writing or typing.

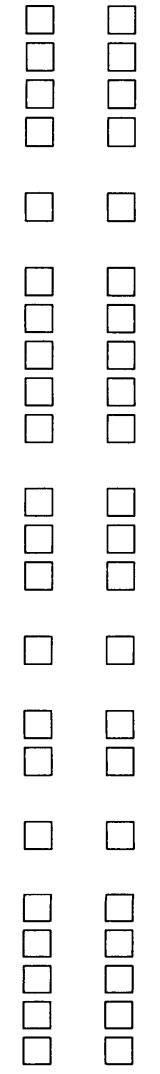

